\title{
Data-driven modeling reveals the Western dominance of global public interest in earthquakes
}

\author{
Jonghun Kam (1) 1,2,3凶 , Jihun Park², Wanyun Shao (i) ${ }^{4}$, Junho Song ${ }^{5}$, Jinhee Kim ${ }^{6}$, Fabrizio Terenzio Gizzi (id ${ }^{7}$, \\ Donatella Porrini id ${ }^{8} \&$ Young-Joo Suh ${ }^{2}$
}

Catastrophic earthquakes stimulate information-seeking behaviors beyond the affected geographical boundaries; however, our understanding of the dynamics of global public interest in earthquakes remains limited. Herein, we harness Big Data to examine the dynamic patterns of global public interest, concerning 17 significant worldwide earthquakes over 2004-2019. We find that the global community shows a higher level of interest when an earthquake occurs in developed countries than in developing countries; however, they lose their interest in the former more rapidly than the latter. Regardless of the affected nation, there is a one- to two-week "golden" time window when attention can be leveraged for fundraising and humanitarian aid. Our findings suggest that European citizens who are highly interested in earthquakes emerge as a potential key community to achieve great inclusiveness in policy interventions to solicit international aid. The findings of this study hint at how Big Data can be utilized to identify "time windows of opportunities" for international humanitarian organizations to efficiently raise donations, charities, and aid resources around the world.

\footnotetext{
${ }^{1}$ Division of Environmental Science and Engineering, Pohang University of Science and Technology, Pohang 37673 , South Korea. ${ }^{2}$ Artificial Intelligence Graduate School, Pohang University of Science and Technology (POSTECH), Pohang 37673, South Korea. ${ }^{3}$ Institute for Convergence Research and Education in Advanced Technology, Yonsei University, Seoul 21983, South Korea. ${ }^{4}$ Department of Geography, The University of Alabama, Tuscaloosa, AL 35487, USA. ${ }^{5}$ Department of Civil, Construction and Environmental Engineering, The University of Alabama, Tuscaloosa, AL 35487, USA. ${ }^{6}$ Division of Humanities and Social Sciences, Pohang University of Science and Technology, Pohang 37673, South Korea. ${ }^{7}$ Institute of Heritage Science, National Research Council (ISPC-CNR), Area della Ricerca, C.da S. Loja, 85050 Tito (Potenza), Italy. ${ }^{8}$ Department of Management, Economics, Mathematics and Statistics, University of Salento, Centro Ecotekne - Via per Monteroni, 73100 Lecce, Italy. ${ }^{凶}$ email: jhkam@postech.ac.kr
} 


\section{Introduction}

ver a half-million people have lost their lives due to earthquakes since 2004 (NGDC/WDS, 2019). In 2010, the Haiti earthquake resulted in 316,000 casualties (3\% of the population) and US $\$ 8$ billion in economic losses (120\% of the country's gross domestic product (GDP)) (Azevedo, 2019). The destructiveness of earthquakes has led to rigorous and perseverant efforts of the scientific community to predict the occurrence of earthquakes. Historically, however, there has been no successful prediction of an earthquake (Merz et al., 2020). This unpredictability of earthquakes results in missing a timely warning of the earthquake occurrence and thus causes massive socio-economic losses, including psychological trauma among earthquake victims (Cénat et al., 2020; Hogg et al., 2014, MayaMondragón et al., 2019; Xu and Wei, 2013). Earthquake-related losses stem from not only the characteristics of earthquakes but also the community's resilience to earthquakes. Particularly, developing countries require timely international humanitarian aid for relief and recovery, while they are mainly dependent on non-requested aid (Besiou et al., 2011; Nagendra et al., 2020; Van Wassenhove, 2006).

Lately, humanitarian organizations are aware of the importance of risk communication during the emergence of natural disasters, not only for effective practical implementation of aids but also for a timely social response that could motivate donors even in countries far away (HHI, 2010). Public interest often increases as traditional mass media and social media report disasters and spread the information "Regarding the Pain of Others" (Moeller, 2006). What's more, the paradigm of disaster journalism has been shifted from reporting objective information, such as the number of deaths and economic losses, to more emotional and engaging forms of storytelling (Cottle, 2013).

In a globalized age, the role of media and communications in disaster mitigation has been changed (Cottle, 2014). There is considerable complexity at work in the media's different construal of disasters, which interacts with political power, surrounding social relations and cultural meanings, as well as processes of global interdependency. Particularly, the spectators in the Western countries react to the distant sufferers that appear frequently in mass media. It raises a question about the ethical role of the media in public life today (Chouliaraki, 2006).

Recently, social media has played a crucial role in disseminating news of earthquakes and their socioeconomic impacts on the local communities through the Internet, thereby increasing public attention and thus attracting more donations around the world than ever before (Gao et al., 2011; Martin, 2013; Russell, 2005). For example, the Red Cross received eight million dollars of charity within two days after the 2010 Haiti earthquake through social media (Gao et al., 2011). Due to a lack of available global data, however, it is still challenging to have a comprehensive understanding of the extent of social media's influence on the social response to disasters around the world.

Technological advances have facilitated the global community's ability to seek and share information via diverse channels, such as interactive web search engines and social media, during almost every phase of a disaster. Near real-time monitoring data of online search, activities enable us to investigate the aggregate dynamics of public interest in disasters at the local, national, and global levels (Dahlberg, 2001). In addition, such data has been used as an alternative source to monitor the magnitude and affected the spatial extent of earthquakes in real-time (Earle, 2010). However, the existing literature is limited on how the aforementioned big data from social monitoring can be effectively utilized to advance our understanding of the dynamics of the social response to disasters across nations (Tan and
Maharjan, 2018). Insufficient transdisciplinary collaborations between the natural and social science communities limit the practical utilization of big data to improve social policymaking (Poel et al., 2018).

Here, we aim to understand and model the dynamics of global public interest in earthquakes, harnessing big data from diverse sources, including the National Oceanic and Atmospheric Administration's (NOAA) Significant Earthquake Database, Google Trends, Wikipedia, and various socioeconomic indices. The null hypothesis of this study is that earthquake-related deaths raise the level of global public interest in earthquakes at the same rate and to the same degree, regardless of the socio-economic development of the affected nation. More specifically, we strive to answer the following questions: (1) What are key factors in the dynamics of global public interest in earthquakes? Are they either physical (earthquake magnitude), socioeconomic (GDP per capita) factors, or others? (2) Which nations are key contributors to the dynamic patterns of global public interest in earthquakes? and (3) How can we leverage the current dynamic patterns of global public interest in earthquakes to improve the current strategies for international aid for earthquake relief and response? Answering these questions will contribute to a better understanding of the dynamic patterns of global public interest in earthquakes and provide an insight into how to improve the current international strategies for earthquake relief and recovery from the lens of big data.

\section{Data for earthquakes and search activity volumes}

The NOAA National Geophysical Data Center/World Data Service (NGDC/WDS) provides a global database for over 6700 significant earthquakes from $2150 \mathrm{BC}$ to the present (NGDC/WDS, 2019). According to the NGDC/WDS database, a significant earthquake is defined as one that caused deaths, incurred at least moderate property damage ( $\sim \$ 1$ million or more), had a magnitude of at least 7.5 on the Richter scale or the modified Mercalli intensity (MMI) scale, and/or generated a tsunami. The database includes the date and time of occurrences, the geographical locations of the epicenters, focal depth, magnitude, maximum MMI intensity, and socioeconomic data for casualties and economic losses.

Google Trends (GT) provides a relative search activity volume of Google product users dating from 2004 and has been used to understand the predictability of real-time economic activities (Choi and Varian, 2012), disease outbreaks (Carneiro and Mylonakis, 2009), and human behaviors (Gunn and Lester, 2013). More recently, the Google Trends data has also been used to reveal dynamic patterns of public awareness of or interest in floods (Thompson et al., 2021) and droughts (Kam et al. 2019; Kim et al., 2019) and its linkages with water use behaviors (Gonzales and Ajami, 2017), as well as the time windows of opportunities to obtain earthquake insurance at the national level (Gizzi et al., 2020). A previous study (Gizzi et al., 2020) proposed a method to generate weighted daily time series of information search activity volume about earthquakes. First, they retrieved monthly GT data using the search topic, "earthquake," from January 2004 through August 2019, and they retrieved daily GT data at the 6-month interval over the study period. Then, they weighted the daily GT data by the monthly GT data and annual percentages of the population using the Internet. Following this method, we first obtain both daily and monthly Google Trends data and the percentages of national populations using the internet and GDP per capita for 62 nations from the World Bank Open Data (Azevedo, 2019). Then, we compute the weighted daily GT data across 62 nations (see Fig. S1 and Extended 


\title{
(a) Casualties of 17 Earthquakes
}

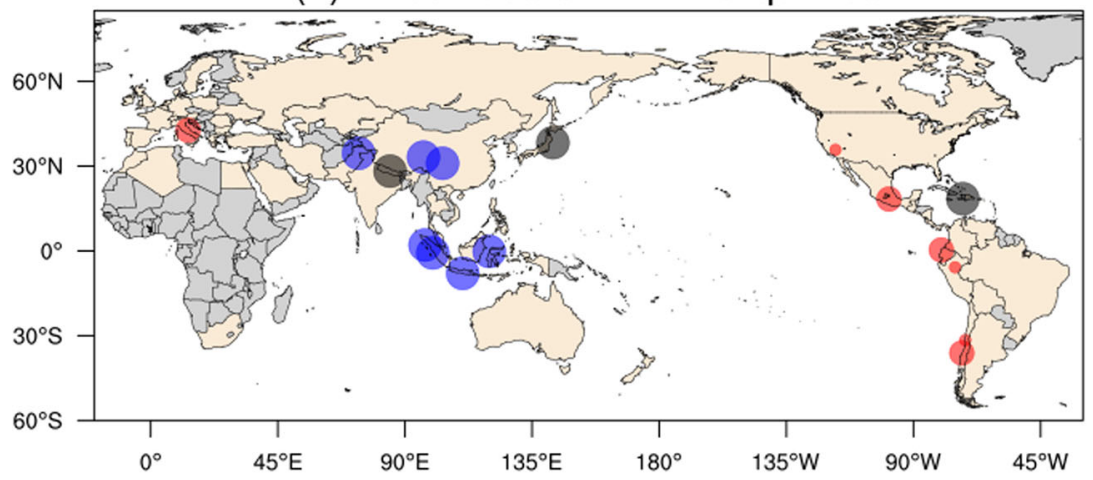

\author{
Most Recognized (7) \\ - Deadliest (7) \\ - Most Recognized \& Deadliest (3) \\ $0<10$ deaths \\ $0<100$ deaths \\ $0<1,000$ deaths \\ $>1,000$ deaths
}

(b) Global Initial Search Activity Volumes of 17 Earthquakes

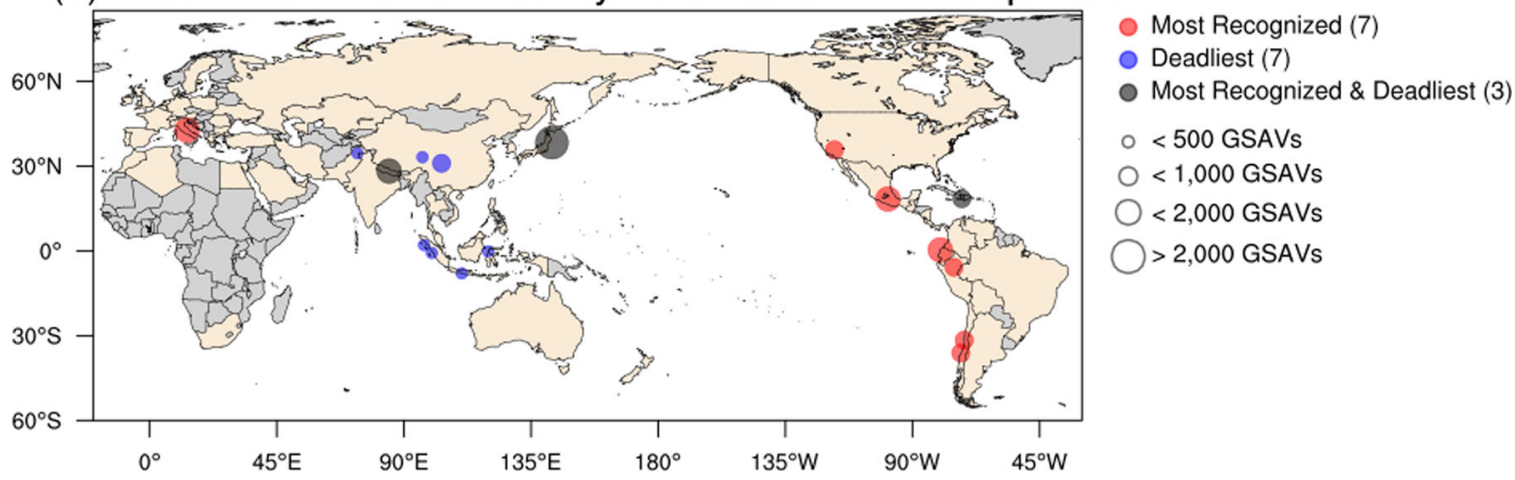

Fig. 1 Discrepancy between the top 10 deadliest and most recognized earthquakes since 2004. casualties (a) and initial global search activity volumes $(G S A V s ;(b))$ of the 17 identified earthquakes. The size of circles in (a) and (b) represents the corresponding earthquake's casualties and initial GSAVs. Black dots depict earthquakes in both categories (deadliest and most recognized). Blue and red dots depict the remainder of the deadliest and most recognized earthquakes, respectively. Areas colored in ivory depict the 62 nations that contribute to the daily GSAV data.

Database S1) that show high search activity volumes over the study period (areas colored in ivory in Fig. 1).

To validate the weighted daily GT data, we use the daily pageview counts of the Wikipedia webpage, "Earthquake" (Wikipedia, 2020). In 2019, an average of 1.5 billion different devices visited Wikipedia per month and traversed over 100 billion documents in total. We collect the daily pageview counts of "Earthquake" from the Wikimedia Analytics Pageview Application Programming Interface (API) by querying daily pageview counts with the article named "Earthquake" from July 2015 (the earliest month for which the daily pageview count data are available) through August 2019 (Fig. 2). The Pearson correlation coefficient between weighted daily GT data and the daily view data of the Wikipedia webpage, "Earthquake" is 0.34 over the overlapped period.

\section{Methods: modeling of global interest in earthquake}

For modeling the dynamics of global public interest in earthquakes, we first compute the initial global search activity volumes per death during the occurrence date of an earthquake, $i$, for the 17 earthquakes. Then, we train an empirical non-linear model for the initial global search activity volumes per death for an earthquake, $i$. This non-linear model is a function of the GDP per capita of the affected nation by an earthquake (Fig. 2a). Then, we use this empirical model to estimate the initial global search activity volume if the casualties and the GDP per capita of the affected nation are given (Eq. (1); see Fig. 3a and the detailed calculations in Extended Database S2).

$$
\operatorname{GSAV}(0, i)=0.0094 * \text { casualties } * \text { GDP per capita }{ }^{2.2706}
$$

where and $i$ is the identification number for an earthquake from the NGDC/WDS database.
Then, we use the observed relationship between the decay rate of GSAVs and the GDP per capita of the affected nations from the 17 earthquakes to model the decay rate $(\alpha)$ of global public interest in earthquakes (Eq. (2); see Fig. 3b).

$$
\alpha=0.018 * \text { GDP per capita }+0.2808
$$

We develop a power-law decay (PLD) model for nation-level public interest in earthquakes for each of the 62 nations, following previous studies (Kam et al., 2019; Sano et al., 2013) (Eq. (3)).

$$
\mathrm{E}[\operatorname{GSAV}(t, i) \mid \operatorname{GSAV}(t-1, i)]=\operatorname{GSAV}(t-1, i) \frac{1}{\{[t-(t-1)]+1\}^{\alpha}}
$$

where $\mathrm{E}[\mathrm{A} \mid \mathrm{B}]$ represents the expected value of $\mathrm{A}$ (herein, global search activity volume (GSAV) at time, $t$ ) given the value of $\mathrm{B}$ (search activity volume at time, $t-1$ ), $t$ is the $t$ th day after the occurrence date of an earthquake (e.g., $t=0$ for the earthquake occurrence date).

Equation (3) can be simplified as Eq. (4).

$$
\mathrm{E}[\operatorname{GSAV}(t, i) \mid \operatorname{GSAV}(0, i)]=\operatorname{GSAV}(0, i) \frac{1}{2^{\alpha t}}
$$

Then, we use the PLD model (Eq. (4)) with the estimated initial global search activity volume (Eq. (1)) and decay rate of global public interest in earthquakes (Eq. (2)) to simulate the daily level of global public interest in the 60 hypothetic earthquakes (six casualties $(10,50,100,200,500,1000$ deaths) times 10 GDPs per capita of an affected nation from 5000 to 50,000 in 2010 US\$ with a constant interval of 5000).

Lastly, we count the number of days when the simulated daily GSAV is $\geq 100$ after the occurrence data, defined as the memory 


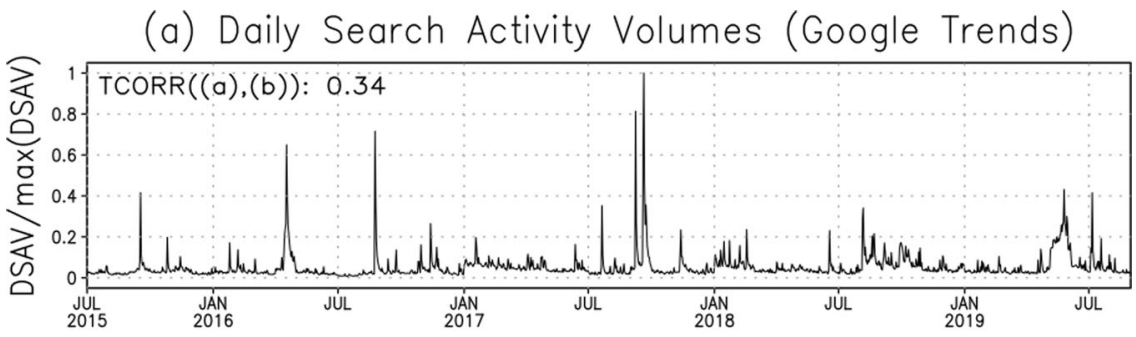

(b) Daily Views (Wikipedia Earthquake Page)

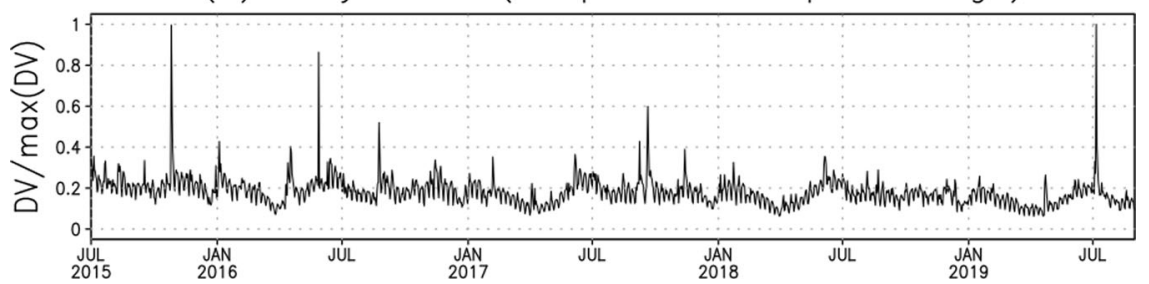

Fig. 2 Consistency between Google Trends and Wikipedia pageview data. Time series of daily GSAVs (a) and daily views of the Wikipedia "Earthquake" webpage (b) from July 2015 to August 2019, which was retrieved on January 1, 2020.

lengths of simulated global public interest in earthquakes (see Fig. 3c and Extended Data 3). We validate the simulated lengths of the simulated global pubic interest during the 17 earthquakes by comparing the observed lengths from the daily Google Trends data (dots in Fig. 3c). Results show that the estimated memory lengths capture well the general pattern of global interest in earthquakes during the 17 earthquakes. The extended datasets have been made publicly available in the Havard Dataverse repository (Kam, 2021).

\section{Methods: Mapping the global network of public interest in earthquake}

To identify which countries are more sensitive to global earthquake events than other countries, we compute out-degree for each country from the global network of national public interest in earthquakes. The out-degree is defined as the number of connections that originate at a departure node (that is, information seeking, but not affected, nations such as green dots in Fig. 4) and point outward to a destination node (that is, affected nations such as black, blue, or red dots in Fig. 4). For efficient visualization, we choose the nine departure nodes with the threshold value of out-degree as 10 and find a weak impact of the threshold value on the results (see Figs. S2 and S3). In this study, the network is constructed using the NetworkX Python library and Gephi, an exploratory graph data analytics tool.

\section{Results: Inconsistency between the deadliest and most recognized earthquakes}

Based on the weighted daily Google Trends and NGDC/WDS data, we identify the 10 deadliest earthquakes based on reported casualties (Table 1) and the 10 most recognized earthquakes based on the ranks of the global search activity volumes (the sums of the national-level search activity volumes from the 62 nations; Table 2). Results show only three earthquakes (black dots in Fig. 1) are found in both top 10 lists: the 2010 Haiti Earthquake, the 2011 Japan Earthquake, and the 2015 Nepal Earthquake while Seven earthquakes are found in the list of the top 10 deadliest (blue dots in Fig. 1) and most recognized earthquakes (red dots), respectively. The magnitudes of the 17 earthquakes range from seven to nine on the Richter scale.

The nations that experienced the deadliest earthquakes all have low per capita GDPs ranging from the US $\$ 3,000$ to $\$ 12,000$ in the 2010 US dollar value (blue dots in Fig. 1), highlighting that low economic development can exacerbate the societal consequences of disasters. For example, four of the top 10 deadliest earthquakes occurred in Indonesia and resulted in casualties ranging from 1000 to 5000 . However, less than $25 \%$ of the population in Indonesia had an Internet access before 2016 that provides crucial information during these events, which indicates that Indonesia's severe vulnerability to earthquake-related deaths stems from a combination of physical exposure and insufficient economic resources and public interest over around the world (HHI, 2010; McCloskey et al., 2005; Siagian et al., 2014). China experienced two deadly earthquakes in 2008 (87,000 deaths) and 2010 (2200 deaths), and only 23\% and $34 \%$ of the country's population, respectively, had an Internet access during these events.

The initial GSAVs on the occurrence dates of the seven deadliest earthquakes ranged 40-514, and moreover, these earthquakes in Indonesia and China received very limited coverage of mass media and the lack of available information (see Table 2). Based on these findings, we speculate that limited information about these earthquakes by mass and social media is likely one of the barriers of securing timely assistance, possibly resulting in additional casualties. Further studies about the role of mass and social media in the association between global public interest and timely assistance are necessary to improve the current international strategies for earthquake relief and response.

In contrast, the initial GSAVs on the occurrence dates of the other (seven) most recognized earthquakes (red dots in Fig. 1) ranged from 750 (from at least eight nations since the maximum of national search activity volume is 100) to 1,800 (18 nations), respectively, and casualties ranged from one to slightly over 600 . The nations that experienced these seven most recognized earthquakes have high GDPs per capita, ranging from US $\$ 11,000$ to $\$ 65,000$, and more than half of their populations had an Internet access (52-87\%) while information search activities have been lately increased during the occurrence of an earthquake (see Table 2). The result indicates that the social infrastructure for the Internet and economic development may be among the driving forces of the lack of global interest in earthquakes that occurred in developing countries, possibly resulting in inconsistency between the lists of the deadliest and most recognized earthquakes.

Results show that the socio-economic development of the affected nations can influence initial GSAVs and their decay rates differently. Nations with higher GDPs per capita affected by an earthquake evince greater levels of initial GSAVs per death (Fig. 3a) while they show a higher decay rate of GSVAs over time (Fig. 3b). That is, the global community is more sensitive to the 
(a)

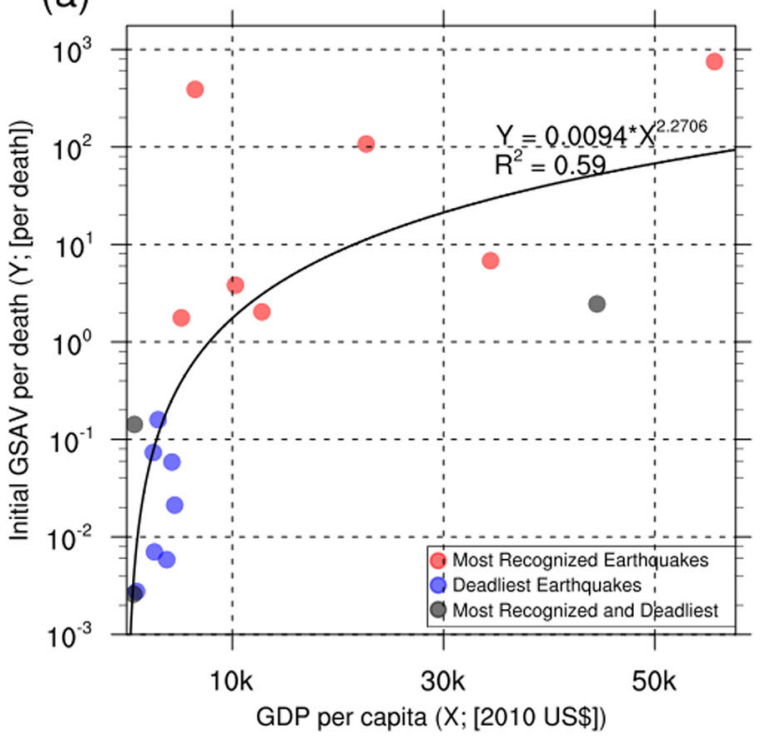

(b)

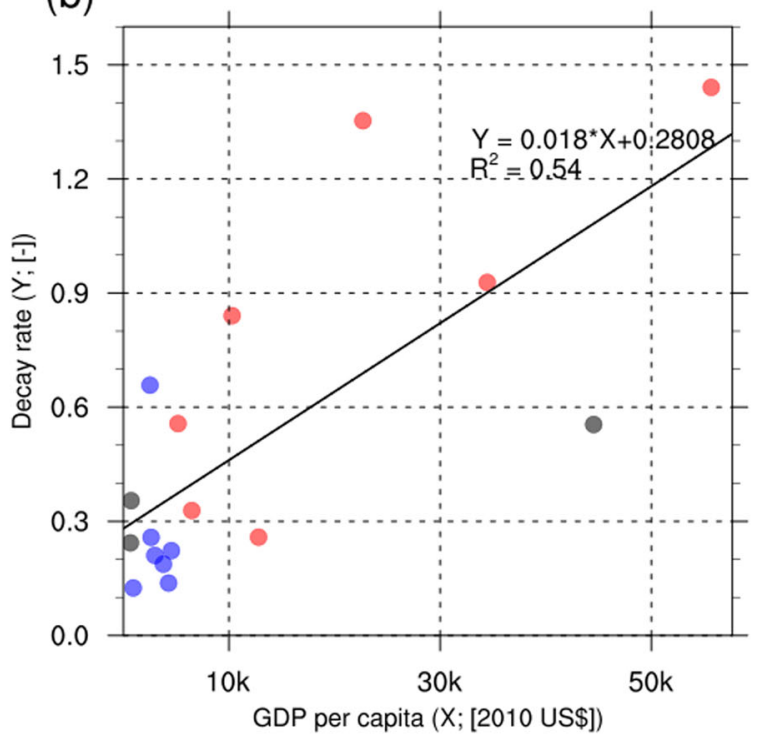

(c)

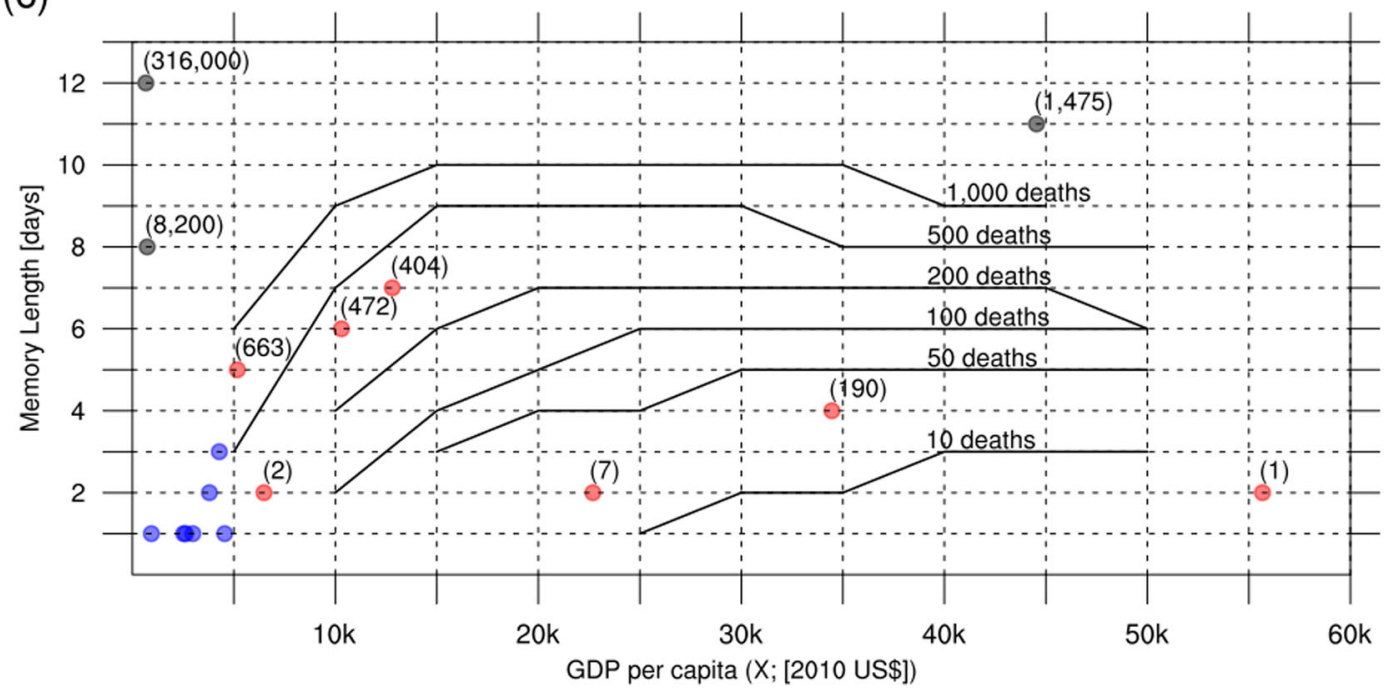

Fig. 3 Sensitivity of simulated global interest in earthquake to casualties and socioeconomic development. In (a) and (b), black solid lines represent the level of global interest per death (initial global SAV divided by the casualties of the corresponding earthquake) and decay rates of global interest in earthquake estimated by the equations (non-linear and linear in (a) and (b), respectively). In (c), black contour lines depict the memory length of simulated global interest in "hypothetical" earthquakes with a range of casualties (10-1,000 deaths) and per capita GDP (5,000-50,000). Dots depict the observed memory lengths of GSAVs of the 17 earthquakes.

emergence of an earthquake in economically developed nations than in developing countries while the global public interest in the former is decreased more quickly than that in the latter.

\section{Results: The Western dominance of global interest in earthquake}

Using data-driven models for global public interest, we construct per capita GDP-death-memory length contours (Fig. $3 c)$. We find that earthquakes in nations with low and high per capita GDPs (below US\$10,000/above US\$30,000) generated global social memory lengths of less than one week with a weak influence from casualties. In contrast, earthquakes in nations with mid-range per capita GDPs (between US\$10,000 and US $\$ 30,000)$ generated a relatively wider range of global social memory concerning the resulting deaths. Overall, the interest in earthquakes of the global community persists for less than two weeks regardless of the socio-economic development level of the affected nation, which we can consider a "golden" time window of opportunities to obtain international aid for earthquake relief and response.

Lastly, we construct a global network map of national public interest in earthquakes that highlights 9 out of the total 62 nations that have not been affected by earthquakes but reveal a high level of search activities during the occurrences of earthquakes elsewhere. (green dots in Fig. 4). The surprising finding is that the highest public interest emerges in countries characterized by a low seismic hazard, according to the Global Earthquake Model (GEM)-Seismic Hazard Map (Pagani et al., 2018). Thus, these Western nations, namely Australia, Belgium, Brazil, Denmark, France, Netherlands, Spain, Switzerland, and the United Kingdom, can drive the dynamics of global public interest in earthquakes despite their distance from the epicenters. This Western dominance of global public interest in earthquakes is likely responsible for the unequal attention to earthquakes occurring in developing vs. developed nations. 


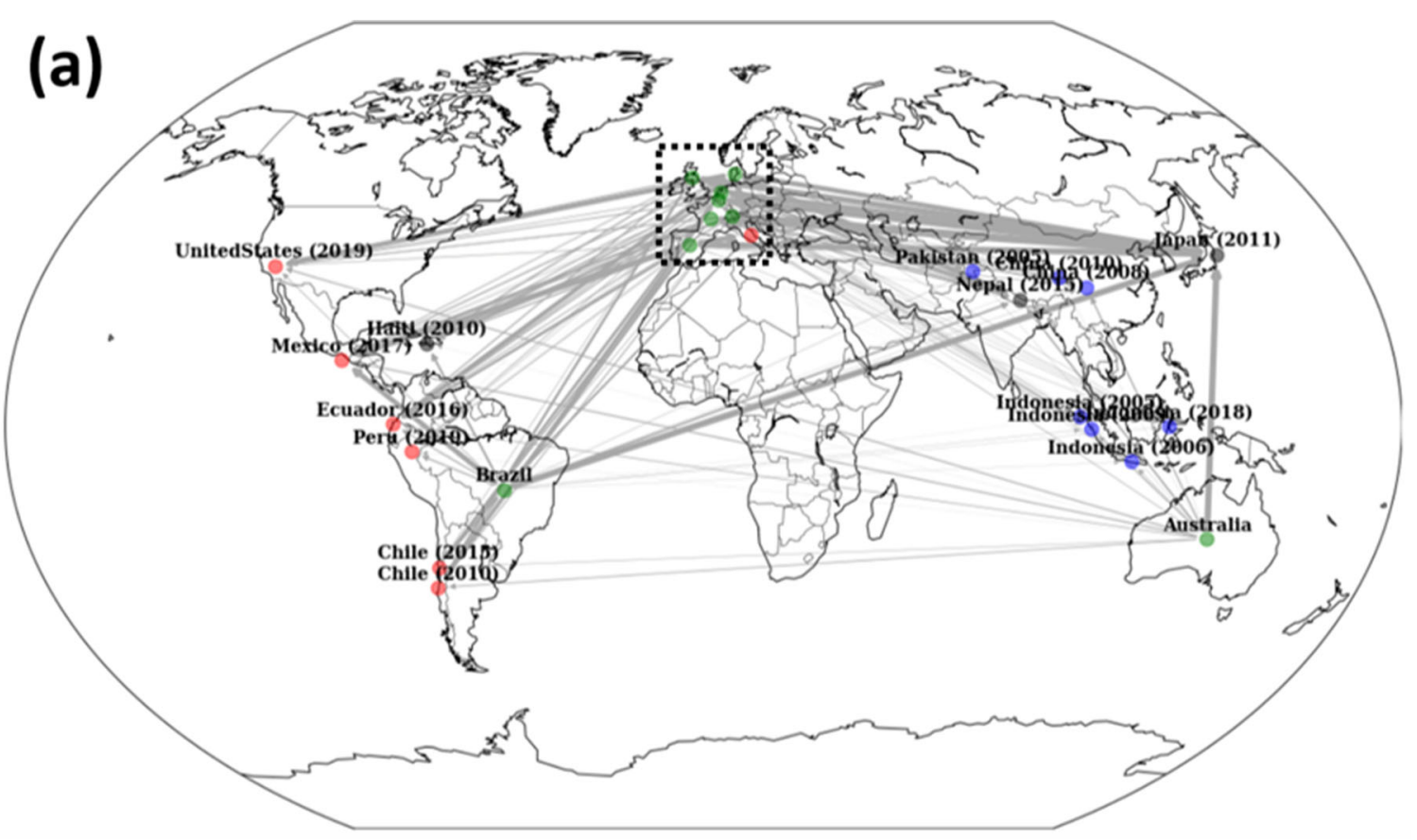

(b)

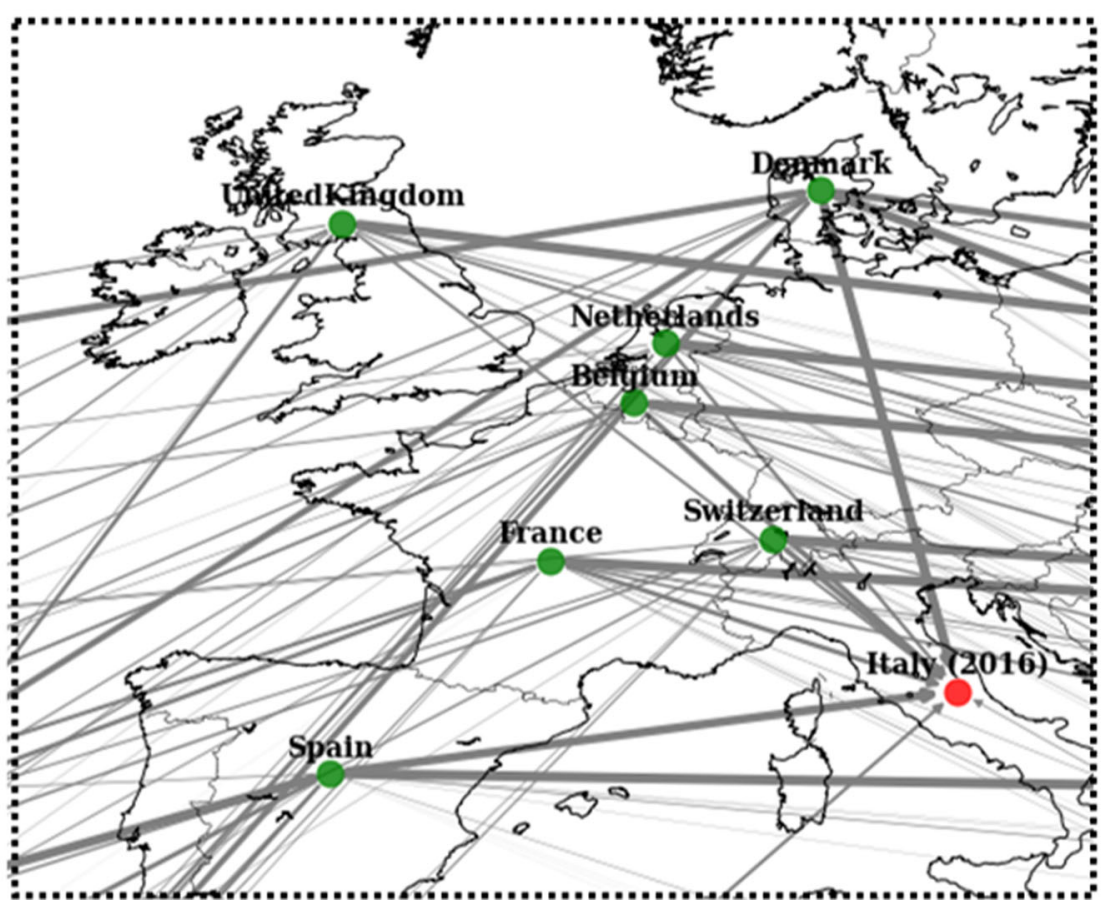

Fig. 4 Dominance of the Western world's contribution to global public interest in the earthquake. In (a), green dots (departure edges) depict unaffected nations with an out-degree over 10, and black, blue, and red dots (destination edges) depict the epicenters of the three most recognized and deadliest earthquakes, the seven deadliest earthquakes, and the seven most recognized earthquakes, respectively. The thickness of the outward arrows from the unaffected nations represents their SAVs. The dotted boxes in (a) are magnified in (b).

\section{Discussion: Potential role of Western countries}

The current findings indicate that we can leverage Western countries to spread public interest in earthquakes and increase awareness of the serious consequences of earthquakes on developing countries. Eventually, it can enhance the effectiveness of international aid and relief efforts. The findings show a different dynamic pattern from analyzing natural disaster news coverage of mass media that revealed great distance bias (i.e., low degree of coverage when disasters occur in a remote area (Berlemann and Thomas, 2019)). Unaffected countries' interest is often influenced by the occurrence of earthquakes in neighboring countries and vicarious experiences, such as reports by relatives/others or media coverage (Becker et al., 2017). The findings highlight the importance of the ethical role of developed nations in securing timely assistance for earthquake relief in developing nations.

According to Google Trends, search activity volumes about earthquake and donation are positively correlated over 2004-2019 (the temporal correlation is above 0.5; see Extended Data 4), indicating a potential opportunity to increase donations, charities, and aid resources. Therefore, humanitarian organizations should leverage publicly available big data, such as Google Trends and Twitter, as a monitoring tool of global public interest 
Table 1 Information for the selected 17 earthquakes.

\begin{tabular}{|c|c|c|c|c|c|c|c|c|c|c|c|}
\hline Type & Year & Month & Day & Tsu & Latitude & Longitude & Mag & Deaths & Injuries & Damage & Country \\
\hline$B$ & 2005 & 3 & 28 & 1 & 2.085 & 97.108 & 8.6 & 1303 & 340 & - & Indonesia \\
\hline$B$ & 2005 & 10 & 8 & 0 & 34.539 & 73.588 & 7.6 & 76213 & 146599 & 6680 & Pakistan \\
\hline B & 2006 & 5 & 26 & 0 & -7.961 & 110.446 & 6.3 & 5749 & 38568 & 3100 & Indonesia \\
\hline B & 2008 & 5 & 12 & 1 & 31.002 & 103.322 & 7.9 & 87652 & 374171 & 86000 & China \\
\hline$B$ & 2009 & 9 & 30 & 1 & -0.72 & 99.867 & 7.5 & 1117 & 1214 & 2200 & Indonesia \\
\hline C & 2010 & 1 & 13 & 1 & 18.457 & -72.533 & 7 & 316000 & 30000 & 8000 & Haiti \\
\hline$A$ & 2010 & 2 & 27 & 1 & -36.122 & -72.898 & 8.8 & 402 & 12000 & 30000 & Chile \\
\hline B & 2010 & 4 & 13 & 0 & 33.165 & 96.548 & 6.9 & 2220 & 12135 & 500 & China \\
\hline $\mathrm{C}$ & 2011 & 3 & 11 & 1 & 38.297 & 142.372 & 9.1 & 1475 & 6157 & 220085.456 & Japan \\
\hline C & 2015 & 4 & 25 & 0 & 28.231 & 84.731 & 7.8 & 8200 & 17866 & 10000 & Nepal \\
\hline$A$ & 2015 & 9 & 17 & 1 & -31.573 & -71.674 & 8.3 & 7 & 14 & 600 & Chile \\
\hline$A$ & 2016 & 4 & 17 & 1 & 0.35 & -80.16 & 7.8 & 663 & 6274 & 3300 & Ecuador \\
\hline$A$ & 2016 & 8 & 24 & 0 & 42.704 & 13.238 & 6.2 & 299 & 368 & 5000 & Italy \\
\hline A & 2017 & 9 & 20 & 1 & 18.339 & -98.68 & 7.1 & 369 & 6000 & 8000 & Mexico \\
\hline$B$ & 2018 & 9 & 28 & 1 & -0.178 & 119.84 & 7.5 & 4340 & 10679 & 1500 & Indonesia \\
\hline$A$ & 2019 & 5 & 26 & 0 & -5.796 & -75.298 & 8 & 2 & 30 & - & Peru \\
\hline A & 2019 & 7 & 4 & 0 & 35.766 & -117.605 & 6.4 & 1 & - & - & USA \\
\hline
\end{tabular}

Table 2 Information for socioeconomic indicators during the selected 17 earthquakes.

\begin{tabular}{|c|c|c|c|c|c|c|c|c|c|c|c|}
\hline Type & Year & Month & Day & $\begin{array}{l}\text { Initial } \\
\text { Global SAVs }\end{array}$ & Wiki & $\begin{array}{l}\text { GDP } \\
\text { per capita }\end{array}$ & Country & Internet users & $\begin{array}{l}\text { Google } \\
\text { Search (ten } \\
\text { thousands) }\end{array}$ & Alpha $(\alpha)$ & $\begin{array}{l}\text { Memory } \\
\text { length [days] }\end{array}$ \\
\hline B & 2005 & 3 & 28 & 95.6491 & $\mathrm{~N} / \mathrm{A}$ & 2524 & Indonesia & 3.6 & 0.808 & 0.658 & 1 \\
\hline B & 2006 & 5 & 26 & 40.2914 & $\mathrm{~N} / \mathrm{A}$ & 2628 & Indonesia & 4.7 & 1.36 & 0.258 & 1 \\
\hline B & 2008 & 5 & 12 & 512.132 & $\mathrm{~N} / \mathrm{A}$ & 3797 & China & 22.6 & 2.43 & 0.187 & 2 \\
\hline B & 2009 & 9 & 30 & 177.881 & $\mathrm{~N} / \mathrm{A}$ & 2979 & Indonesia & 7 & 2.9 & 0.21 & 1 \\
\hline B & 2010 & 4 & 13 & 47.0828 & $\mathrm{~N} / \mathrm{A}$ & 4550 & China & 34.3 & 4.04 & 0.223 & 1 \\
\hline C & 2011 & 3 & 11 & 3614.04 & $\mathrm{~N} / \mathrm{A}$ & 44,538 & Japan & 79 & 9.48 & 0.554 & 11 \\
\hline C & 2015 & 4 & 25 & 1168.66 & $\mathrm{~N} / \mathrm{A}$ & 732 & Nepal & 17.5 & 14.1 & 0.354 & 8 \\
\hline A & 2015 & 9 & 17 & 750.723 & 10,944 & 22,688 & Chile & 76.6 & 14.3 & 1.353 & 2 \\
\hline A & 2016 & 4 & 17 & 1171.92 & 13,166 & 5176 & Ecuador & 54 & 13.9 & 0.557 & 5 \\
\hline A & 2016 & 8 & 24 & 1292.72 & 16,990 & 34,459 & Italy & 61 & 13.1 & 0.928 & 4 \\
\hline
\end{tabular}

The Google Search data were retrieved using the advanced search option specifying the occurrence date of an earthquake in Google web search engine (see Fig. S4). Memory lengths were counted from the number of days when the initial GSAV is $\geq 100$ (see External Database S3).

in earthquakes by country and over time following the earthquake, to raise fundraising and aid resources efficiently. Such big data will help arrange ad hoc information and communication campaigns almost in real-time with spikes of online search activity, thus promptly capturing the potential interest of donors, particularly from citizens of Western nations. It will also prevent public interest from "watering down" due to the passing of time. In addition, policymakers and stakeholders can use the two-week "golden" time window as a "Trojan horse" to involve more people in earthquake preparedness, including mitigation action recovery tools, and efforts to alleviate damage (Dowrick, 2003; Gizzi et al., 2020; Nigg, 2000; Spittal et al., 2008).

\section{Conclusions}

This study demonstrates evidence of inequalities in global public interest in earthquakes and highlights the dominancy of Western nations in contributing to the observed behavior patterns of information seeking around the world, by harnessing multiple data sources. The latter finding of the role of Western nations can be explained by long-understood conditions accruing from socioeconomic development; whereas people living in societies within less developed economies are constrained to considerations of immediate basic needs, those living in more prosperous nations have more opportunity to pursue knowledge for selfactualization. Nonetheless, our results show that the social response to earthquakes varies even in developed countries.

Considering the complexity of social dynamics at the global level and the intrinsic singularity of an earthquake, other information such as the proximity of the earthquake's epicenter to other countries, the number of available information transfer channels, and the public's education level may also have an explanatory power for the dynamics of global pubic interest in earthquakes. Still, the findings of this study suggest the utility of big data for solving the "hierarchy of global suffering" from natural disasters (Joye, 2009) and emphasize the importance of 
inclusiveness in earthquake relief and mitigation. Lastly, the findings of this study encourage the global community to have a balanced interest in earthquakes and focus on soliciting aid during the first 2 weeks following an earthquake in order to maximize the effectiveness of recovery aid and efforts.

\section{Data availability}

The datasets analyzed in this study are available in the Dataverse repository: https://doi.org/10.7910/DVN/83UZ9X.

Received: 20 January 2021; Accepted: 27 September 2021;

Published online: 20 October 2021

\section{References}

Azevedo JP (2011) "WBOPENDATA: Stata module to access World Bank databases", Statistical Software Components S457234, Boston College Department of Economics. http://ideas.repec.org/c/boc/bocode/s457234.html

Becker JS, Paton D, Johnston DM, Ronan KR, McClure J (2017) The role of prior experience in informing and motivating earthquake preparedness. Int $\mathrm{J}$ Disaster Risk Reduct 22:179-193

Berlemann M, Thomas T (2019) The distance bias in natural disaster reportingempirical evidence for the United States. Appl Econ Lett 26(12):1026-1032

Besiou M, Stapleton O, Van Wassenhove LN (2011) System dynamics for humanitarian operations. J Humanit Logist Supply Chain Manag. 1:78-103

Carneiro HA, Mylonakis E (2009) Google trends: a web-based tool for real-time surveillance of disease outbreaks. Clin Infect Dis 49(10):1557-1564

Cénat JM, McIntee S-E, Blais-Rochette C (2020) Symptoms of posttraumatic stress disorder, depression, anxiety and other mental health problems following the 2010 earthquake in Haiti: a systematic review and meta-analysis. J Affect Disord. 273:55-85

Choi H, Varian H (2012) Predicting the present with Google Trends. Econ Rec 88:2-9 Chouliaraki L (2006) The spectatorship of suffering. Sage.

Cottle S (2013) Journalists witnessing disaster. Journal Stud 14(2):232-248

Cottle S (2014) Rethinking media and disasters in a global age: what's changed and why it matters. Media War Conflict 7(1):3-22

Dahlberg L (2001) Democracy via cyberspace: mapping the rhetorics and practices of three prominent camps. New Media Soc 3(2):157-177

Dowrick DJ (2003) Earthquake risk reduction actions for New Zealand. Bull N Z Soc Earthq Eng 36(4):249-259

Earle P (2010) Earthquake twitter. Nat Geosci 3(4):221-222

Gao H, Barbier G, Goolsby R (2011) Harnessing the crowdsourcing power of social media for disaster relief. IEEE Intell Syst 26(3):10-14

Gizzi FT, Kam J, Porrini D (2020) Time windows of opportunities to fight earthquake under-insurance: evidence from Google Trends. Humanit Soc Sci Commun 7(1):1-11

Gonzales P, Ajami N (2017) Social and structural patterns of drought-related water conservation and rebound. Water Resour Res 53(12):10619-10634

Gunn III JF, Lester D (2013) Using google searches on the internet to monitor suicidal behavior. J Affect Disord 148(2-3):411-412

HHI (2010) Disaster Relief 2.0: The future of information sharing in humanitarian emergencies. HHI, pp. 72-72.

Hogg D, Kingham S, Wilson TM, Griffin E, Ardagh M (2014) Geographic variation of clinically diagnosed mood and anxiety disorders in Christchurch after the 2010/11 earthquakes. Health Place 30:270-278

Joye S (2009) The hierarchy of global suffering: a critical discourse analysis of television news reporting on foreign natural disasters. J Int Commun 15(2):45-61

Kam J (2021) Replication data for: data-driven modeling reveals the Western dominance of global pubic interest in earthquakes. Harvard Dataverse.

Kam J, Stowers K, Kim S (2019) Monitoring of drought awareness from google trends: a case study of the 2011-17 California drought. Weather Clim Soc 11(2):419-429

Kim S, Shao W, Kam J (2019) Spatiotemporal patterns of US drought awareness. Palgrave Commun 5(1):1-9

Martin JA (2013) Disasters and donations: the conditional effects of news attention on charitable giving. Int J Public Opinion Res 25(4):547-560

Maya-Mondragón J, Sanchez-Roman FR, Palma-Zarco A, Aguilar-Soto M, BorjaAburto VH (2019) Prevalence of post-traumatic stress disorder and depression after the September 19th, 2017 earthquake in Mexico. Arch Med Res 50(8):502-508

McCloskey J, Nalbant SS, Steacy S (2005) Earthquake risk from co-seismic stress. Nature 434(7031):291-291
Merz B, Kuhlicke C, Kunz M, Pittore M, Babeyko A, Bresch DN, Domeisen DI Feser F, Koszalka I, Kreibich H (2020) Impact forecasting to support emergency management of natural hazards. Rev Geophys 58:e2020RG000704

Moeller SD (2006) "Regarding the pain of others": media, bias and the coverage of international disasters. J Int Affairs 50:173-196

Nagendra NP, Narayanamurthy G, Moser R (2020) Management of humanitarian relief operations using satellite big data analytics: the case of Kerala floods. Ann Oper Res 1-26. https://doi.org/10.1007/s10479-020-03593-w

NGDC/WDS (2019) National Geophysical Data Center/World Data Service. NOAA, National Centers for Environmental Information.

Nigg J (2000) Predicting earthquakes: science, pseudoscience, and public policy paradox. Prediction: science, decision making, and the future of nature. Island Press, Covelo, pp. 135-156

Pagani M, Garcia-Pelaez J, Gee R, Johnson K, Poggi V, Styron R, Weatherill G, Simionato M, Viganò D, Danciu L (2018) Global Earthquake Model (GEM) Seismic hazard map (version 2018.1-December 2018). https://doi.org/ 10.13117/GEM-GLOBAL-SEISMIC-RISK-MAP-2018

Poel M, Meyer ET, Schroeder R (2018) Big data for policymaking: great expectations, but with limited progress? Policy Internet 10(3):347-367

Russell TE (2005) The humanitarian relief supply chain: analysis of the 2004 South East Asia earthquake and tsunami. Massachusetts Institute of Technology.

Sano Y, Yamada K, Watanabe H, Takayasu H, Takayasu M (2013) Empirical analysis of collective human behavior for extraordinary events in the blogosphere. Phys Rev E 87(1):012805

Siagian TH, Purhadi P, Suhartono S, Ritonga H (2014) Social vulnerability to natural hazards in Indonesia: driving factors and policy implications. Nat Hazards 70(2):1603-1617

Spittal MJ, McClure J, Siegert RJ, Walkey FH (2008) Predictors of two types of earthquake preparation: survival activities and mitigation activities. Environ Behav 40(6):798-817

Tan YJ, Maharjan R (2018) What googling trends tell us about public interest in earthquakes. Seismol Res Lett 89(2A):653-657

Thompson JJ, Wilby RL, Matthews T, Murphy C (2021) The utility of Google Trends as a tool for evaluating flooding in data-scarce places. Area 1-10. https://doi.org/10.1111/area.12719

Van Wassenhove LN (2006) Humanitarian aid logistics: supply chain management in high gear. J Oper Res Soc 57(5):475-489

Wikipedia (2020) Earthquake, Retreived on July, 30, 2020 from https:// en.wikipedia.org/wiki/Earthquake

Xu J, Wei Y (2013) Social support as a moderator of the relationship between anxiety and depression: an empirical study with adult survivors of Wenchuan earthquake. PLoS ONE 8(10):e79045

\section{Acknowledgements}

We thank NOAA National Centers for Environmental Information, Google Trends and Wikipedia for making available the historical earthquake, search engine query data, and daily view data, respectively. JK was partially supported by the Basic Research Program through the National Research Foundation of Korea(NRF) funded by the MSIT(NRF-2020R1A4A101881812). JP and Y-JS were supported by the Institute of Information \& communications Technology Planning \& Evaluation (IITP) grant (No. 2019-0-01906, Artificial Intelligence Graduate School Pro$\operatorname{gram}(\mathrm{POSTECH}))$. WS was supported by the National Academies of Sciences, Engineering, and Medicine Gulf Research Program (grant 2000010990).

\section{Author contributions}

JK conceived this manuscript, JK, JP, and JS compiled the data, conducted the data analysis, and produced the figures. JK and JP interpreted the results of the data analysis. JK mainly wrote the manuscript and all the authors equally contributed to discussion and writing.

\section{Competing interests}

The authors declare no competing interests.

\section{Additional information}

Supplementary information The online version contains supplementary material available at https://doi.org/10.1057/s41599-021-00914-7.

Correspondence and requests for materials should be addressed to Jonghun Kam.

Reprints and permission information is available at http://www.nature.com/reprints

Publisher's note Springer Nature remains neutral with regard to jurisdictional claims in published maps and institutional affiliations. 
(c) (i) Open Access This article is licensed under a Creative Commons Attribution 4.0 International License, which permits use, sharing, adaptation, distribution and reproduction in any medium or format, as long as you give appropriate credit to the original author(s) and the source, provide a link to the Creative Commons license, and indicate if changes were made. The images or other third party material in this article are included in the article's Creative Commons license, unless indicated otherwise in a credit line to the material. If material is not included in the article's Creative Commons license and your intended use is not permitted by statutory regulation or exceeds the permitted use, you will need to obtain permission directly from the copyright holder. To view a copy of this license, visit http://creativecommons.org/ licenses/by/4.0/.

(C) The Author(s) 2021 